\title{
INCIDENCE OF TUBERCULOSIS INFECTION IN CHILDREN TRAVELLING TO COUNTRIES WITH HIGH PREVALENCE OF TUBERCULOSIS (PRELIMINARY RESULTS).
}

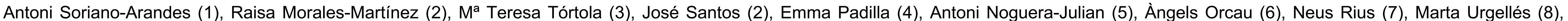

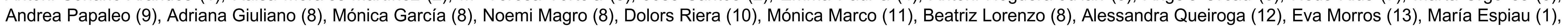
Andrea Martín-Nalda (1), Marta García-Bernal (14), Robert Cilveti (14), Maria Teresa Pascual (7), Joan A. Caylá (15), Jordi Gómez i Prat (2), Tomàs M. Pérez-Porcuna (8,14,16)

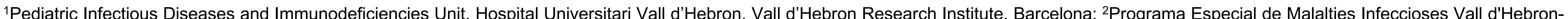

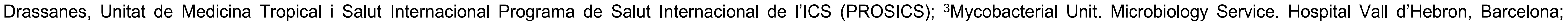

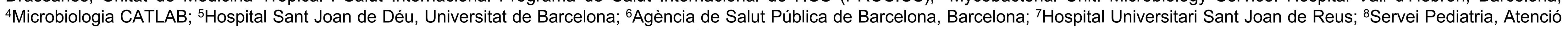

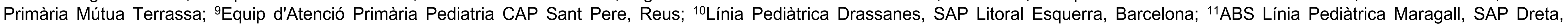

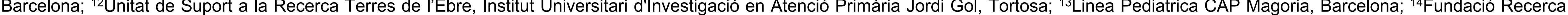

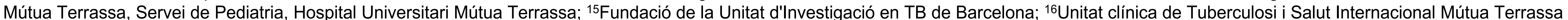

Background: $\quad$ Results:

- Two-hundred sixty-four children were recruited, 252 analysed (12 not TST-screened).

tuberculosis (TB) travelling abroad to endemic TB - Median [IQR] age was 5.83[2.84-9.02] years; $50.8 \%$ female; 86.7\% autochthonous; $4.8 \%$ BCG-vaccinated;

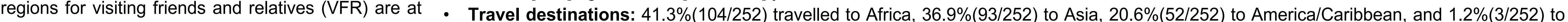
risk of latent TB infection (LTBI).

- The identification of risk factors associated with TB infection would allow us to improve screening programmes pre-post travel.

- The aim of this study was to determine the incidence and risk factors associated with LTBI in VFR children travelling to countries with high-incidence of TB.

\section{Methods:}

- A multicentric prospective cohort study is being developed since 2017, including different health-care levels, of a cohort of VFR children <15-year-old travelling to high-incidence TB countries of $>50$ cases $/ 10^{5}$ inhabitants.

- Children were screened before travelling with a tuberculin skin test (TST), LTBI was defined as a TST conversion and/or a positive QuantiFERON-TB Plus $₫(Q F T)$ performed after the trip.

- Statistical analysis was carried out through Stata ${ }^{2} 13$.

- Ethical approval was obtained from all the participating centres.

Financial support: Instituto Carlos III, Ministerio de Economía Industria y Competitividad, Gobierno de España, Acción estratégica de salud (AES PI16-314); Sociedad Española de Pneumología (SEPAR) Beca PII-TB 2016; Pla Estratègic de Recerca i Innovació en Salut (PERIS), Departament de Sanitat i Seguretat Social Generalitat de Catalunya (SLT006/17/144)

Acknowledgements: Programa de Tuberculosi, Agència de Salut Pública de Catalunya, Departament de Salut, Generalitat de Catalunya.

\begin{abstract}
Eastern Europe (figure 1)
\end{abstract}

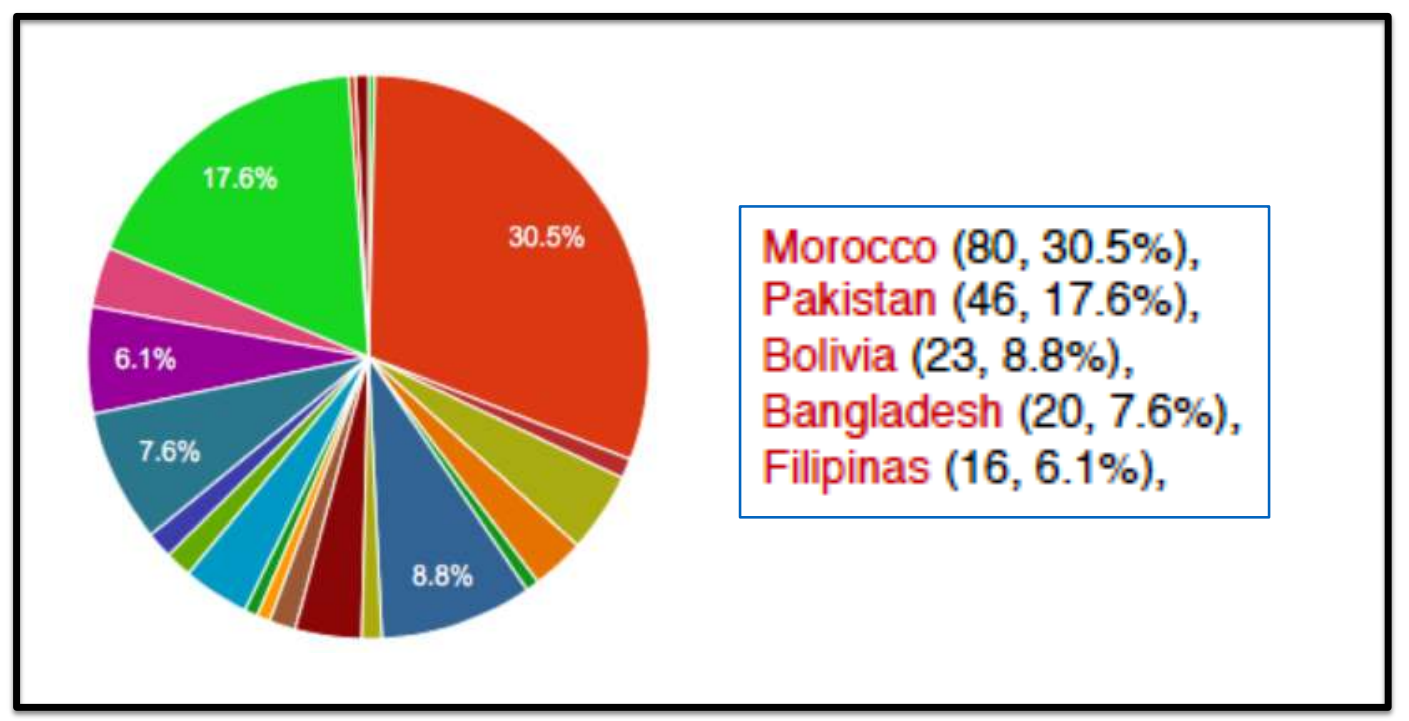

Figure 1. Most important travel destinations of the recruited children

Median [IQR] travel duration was 1.3 [1.0-1.8] months.

- TST was performed at a median [IQR] of 16 [7-22] days before departure's date

- Pre-travel TST results: 4/252 (1.6\%;95\%Cl:0.6-4.2\%) were TST positive: 3/252(1.2\%;95\%Cl:0.4-3.6\%) LTBI, and 1/252(0.4\%) because of BCG vaccination.

- Post-travel TST results: among 187 children, TST and/or QFT were performed in $74.9 \%(95 \% \mathrm{Cl}: 68.1-80.6 \%)$ of them at a median [IQR] of 74 [53-95] days, and no LTBI have been detected due to travel itself.

- TST was performed at a median [IQR] of 74 [55-95] days after returning travel date.

- Median [IQR] household familiar cohabitants during the stay at travel destination was of 7 [6-9.75] individuals.

- Most of the children (57.4\%) travelled to urban areas, and nearly $20 \%$ lived there with adult active smokers.

- Known TB contact during the travel was reported by $2.0 \%$ of the subjects.

Conclusions:

- No LTBI cases have been detected after travelling in these preliminary results.

- However, 3 children with LTBI $(1.2 \% ; 95 \% \mathrm{Cl}: 0.4-3.6 \%)$ were diagnosed due to the study itself before the trip.

- VFR children could be a high-risk group for LTBI susceptible to be screened. 